\title{
Knowledge of Breast Cancer and Breast Self-Examination Practice among Iranian Women in Hamedan, Iran
}

\author{
Mehrnoosh Akhtari-Zavare ${ }^{1 *}$, Abbas Ghanbari-Baghestan², Latiffah A Latiff', \\ Nasrin Matinnia ${ }^{3}$, Mozhgan Hoseini ${ }^{4}$
}

\begin{abstract}
Background: In Iran, breast cancer is the most prevalent cancer in women and a major public health problem. Methods: A cross sectional study was carried out to determine knowledge on breast cancer and breast selfexamination (BSE) practices of $\mathbf{3 8 4}$ females living in the city of Hamadan, Iran. A purposive sampling method was adopted and data were collected via face-to-face interviews based on a validated questionnaire developed for this study. Results: Among respondents 268 (69.8\%) were married and $144(37.5 \%)$ of the respondents reported having a family history of breast cancer. One hundred respondents $(26.0 \%)$ claimed they practiced BSE. Level of breast cancer knowledge was significantly associated with BSE practice $(p=0.000)$. There was no association with demographic details $(p<0.05)$. Conclusion: The findings showed that Iranian women's knowledge regarding breast cancer and the practice of BSE is inadequate. Targeted education should be implemented to improve early detection of breast cancer.
\end{abstract}

Keywords: Breast cancer - breast self-examination - knowledge - Iran

Asian Pac J Cancer Prev, 15 (16), 6531-6534

\section{Introduction}

Breast cancer is the most common cause of cancer morbidity and mortality among women in most parts of the world including Iran (Mousavi et al., 2009; Loh and Chew, 2011). According to latest statistics, the mean age of breast cancer in Iranian women was decreased about ten years and reach from 40 to 30 years old (Fouladi et al., 2011), with incidence rate 22 per 100,000 population (Mousavi et al., 2009).

In Iran, the staging upon presentation among women is still poor, most women (72\%) were diagnosed with a tumor over $2 \mathrm{~cm}$ and $63 \%$ of them had lymph node involvement at the time of diagnosis (Mousavi et al., 2009; Fouladi et al., 2011). The social and cultural perceptions of breast cancer in Iran are the most important contributors to the advanced stage of presentation. Early detection of breast cancer plays an important role in reducing its morbidity and mortality. Breast self-examination (BSE), clinical breast examination and mammography are recommended for detecting breast cancer at an early stage (Ersin and Bahar, 2013; Yilmaz et al., 2013). Although, there is debate surrounding the efficacy of routine BSE in early detection of breast cancer (Giridhara et al., 2011). BSE is still an important screening tool for early detection of breast cancer in developing countries, because it is cheap, widely available, and does not require complex technical training (Giridhara et al., 2011). Overall, practicing BSE allows a woman to be familiar with her normal breast structure and helps her to learn to notice any unusual changes in her breast tissue (Smith et al., 2009).

Despite the relative benefits of BSE, its application remains low (Canbulat and Uzun, 2008). Study conducted among 550 women in Turkey, showed that less than half of the samples practiced BSE but only $16 \%$ reported that they performed BSE every month (Yurdakos and Gulhan, 2013). Similar results were found among Malaysian female, which showed only $36.7 \%$ conducting BSE practice. In a recent research, young Malaysian female were noted not know how to perform a BSE (Akhtari-Zavare et al., 2011). Studies have shown sociodemographic characteristics, knowledge on breast cancer are associated with BSE practice (Giridhara et al., 2011; Yurdakos and Gulhan, 2013).

The purpose of the current study was to identify the rate of practicing BSE and breast cancer knowledge in a sample of Iranian women living in city of Hamadan. Understanding Iranian women's knowledge related to breast cancer and BSE practices will help health care professionals to choose more effective health education programmes and potentially to increase women's screening practices. 


\section{Materials and Methods}

Study design

A cross sectional study was conducted from Jun 2012 to September 2012 among women who were referred to the health care and medical centers in Hamadan city, Iran. A total of 384 women were selected by using purposive sampling method.

\section{Questionnaire}

Data were collected via face-to-face interviews based on a structured questionnaire which was developed by the authors based on an extensive review of the literature. The questionnaire was pretested among 30 female for checking the clarity of the items. The questionnaire consisted of two parts: Part I of the questionnaire was included socio-demographic characteristics contained age, level of education, marital status, occupation, personal history of breast problem and family history of breast cancer. Part II of the questionnaire was breast cancer knowledge questions included: having ever heard/ read about breast cancer; sources of information; and 46 knowledge questions on symptoms (10 items), risk factors of breast cancer (13 items), screening tests ( 8 items), knowledge of BSE (12 items) and BSE practices (3 items). Responses were measured using the nominal scale of "True", "False" and "Do not know". One point was given for a correct answer and zero for an incorrect or no answer. The knowledge level was categorized as "low" for scores within 0-49\%, "moderate" for scores within 50-79\% and "high" for scores within 80-100\% (Lamport and Andre, 1993).

\section{Data analysis}

Data was analyzed by using PASW Statistics 19.0 program. Normality tests were done and all of the quantitative data were found to be normally distributed. Descriptive statistics were obtained for all the variables studied. Pearson Chi-Square was used to test for association between categorical variables. Parametric

Table 1. Distribution of Knowledge on Breast Cancer and Breast Cancer Screening $(n=384)$

\begin{tabular}{|c|c|c|c|c|}
\hline \multirow[t]{2}{*}{ Breast cancer } & \multicolumn{3}{|c|}{ Level of knowledge } & \multirow[t]{2}{*}{ Mean (SD) } \\
\hline & $\begin{array}{l}\text { Low } \\
\text { Freq. }(\%)\end{array}$ & $\begin{array}{l}\text { Moderate } \\
\text { Freq. (\%) }\end{array}$ & $\begin{array}{l}\text { High } \\
\text { Freq. }(\%)\end{array}$ & \\
\hline \multicolumn{5}{|c|}{ Risk factor breast cancer } \\
\hline & $197(51.3)$ & $141(36.7)$ & $46(12.0)$ & $5.4 \pm 1.7$ \\
\hline \multicolumn{5}{|c|}{ Symptoms of breast cancer } \\
\hline & $209(54.4)$ & $144(37.5)$ & $31(8.1)$ & $3.2 \pm 1.6$ \\
\hline \multicolumn{5}{|c|}{ CBE and mammography } \\
\hline & $278(72.4)$ & $50(13.0)$ & $56(14.6)$ & $1.7 \pm 1.3$ \\
\hline BSE & $217(56.5)$ & $110(28.6)$ & $57(14.8)$ & $6.7 \pm 2.6$ \\
\hline \multicolumn{5}{|c|}{ Overall knowledge on BC and BSE } \\
\hline & $192(50.0)$ & $113(29.4)$ & $79(20.6)$ & $17.2 \pm 5.6$ \\
\hline
\end{tabular}

test such as independent sample t-test were employed to determine differences between the BSE practice category and the knowledge score of risk factors, symptoms of breast cancer, knowledge of BSE. The level of statistical significance was set at $\alpha<0.05$.

\section{Results}

\section{Response rate}

A total of 400 respondents were selected as the sample of the study. However, 16 respondents $(4.20 \%)$ refused to participate, and hence, 384 women were interviewed in this study. The response rate derived in this study was $95.5 \%$.

\section{General characteristics of the subjects}

The mean age of the respondents was 30.0土9.1 with a range from 18-52 years old. Most of the women were married $268(69.8 \%)$, secondary level education $181(47.1 \%)$ while $4.9 \%$ of women were illiterate. Only $107(27.9 \%)$ of the women were gainfully employed while the rest were housewives. Family history of breast cancer was reported by 144 (37.5\%) of the respondents while 83 (21.6\%) had history of breast problems. The most common problem experienced was pain $72(86.7 \%)$. Among the remaining women, 7 subjects $(7.2 \%)$ had a lump which had been diagnosed and 4(4.8\%) women reported having discharge from the nipple.

\section{Breast self-examination practice}

Based on the result obtained from this study, the percentage of participants who performed BSE was $100(26.0 \%)$ while the percentage of female who not performed BSE was $74.0 \%$. Among those who practice BSE, most of them practice BSE occasionally 53 (13.8\%). The commonest reason given for not doing BSE was a lack of knowledge on how to do it 202 (72.1\%). Other reasons included: forgetfulness 35 (12.3\%), fear of finding a mass $25(8.8 \%)$, not necessary $15(5.2 \%)$, and lack of time $7(2.5 \%)$.

Also, there were not statistically significant relationship between those practicing BSE and those who did not practice BSE with family history of breast cancer of respondents, personal history of breast problem, age, education level and age group. Only there were statistically significant relationship between those practicing BSE and those who did not practice BSE with marital status of respondents $\left(\mathrm{x}^{2}=6.68, \mathrm{df}=1, \mathrm{p}=0.010, \mathrm{n}=384\right)$.

Among the respondents, 230 (97\%) of them had heard or read about breast cancer and media was the major source of information on BSE (34\%). Brochure (24\%), friends $(17 \%)$, doctor $(14 \%)$ and nurse $(11 \%)$ were mentioned as other sources of information on BSE practice.

Table 2. Comparison of the Mean Knowledge of BC, BSE Score for Those Having BSE and Those did not (n=384)

\begin{tabular}{|c|c|c|c|c|}
\hline Knowledge of Breast cancer & $\begin{array}{c}\text { Performing BSE } \\
(\mathrm{n}=100) \text { Mean }(\mathrm{SD})\end{array}$ & $\begin{array}{l}\text { Not Performing BSE } \\
(n=284) \text { Mean }(\mathrm{SD})\end{array}$ & T- value & $\mathrm{p}$ value \\
\hline Risk factor breast cancer & $5.6 \pm 1.8$ & $5.3 \pm 1.7$ & 1.3 & 0.17 \\
\hline Symptoms of breast cancer & $4.0 \pm 1.6$ & $3.5 \pm 1.6$ & 2.6 & $0.009 *$ \\
\hline CBE and Mammography & $2.1 \pm 1.3$ & $1.6 \pm 1.2$ & 3.2 & $0.001 *$ \\
\hline Knowledge score of BSE & $7.4 \pm 2.4$ & $6.5 \pm 2.6$ & 2.9 & $0.003 *$ \\
\hline
\end{tabular}


Knowledge on breast cancer and breast cancer screening

The forty-six questions on knowledge of breast cancer included: risk factors, symptoms of breast cancer; and early detection methods of breast cancer (CBE, mammography and BSE). The mean knowledge score was $17.2(\mathrm{SD}=5.6)$, which meant that correct answers were given to less than half of the questions (Table 1). The highest knowledge score related to breast self-examination and the lowest to CBE \& mammography.

Comparison of the mean knowledge of breast cancer and breast self-examination for those who practice BSE and those who did not practice BSE

Table 2 shows the comparisons of mean knowledge score of breast cancer and mean knowledge score of BSE between those practicing BSE and those who did not practice BSE. The results show that there were statistically significant differences between those practicing BSE and those who did not practice BSE with symptoms of breast cancer $(\mathrm{t}=2.6, \mathrm{p}=0.009), \mathrm{CBE} \&$ mammography $(\mathrm{t}=3.2$, $\mathrm{p}=0.001)$ and knowledge score of BSE $(\mathrm{t}=2.9, \mathrm{p}=0.003)$ at (p value $<0.05)$.

\section{Discussion}

Breast self-examination is a simple, cost-free, and easily applicable method. BSE, although not having been shown to be effective in reducing mortality, is remarkably effective in increasing self-responsibility about health, encouraging adoption of preventive health behaviors, and creating awareness about breast cancer among women (Habib et al., 2010; Suh et al., 2012). However, several studies conducted in Iran demonstrated that usually women do not perform BSE (Ahmadian et al., 2012; Parsa et al., 2008). In a study by Noroozi et al. (2011) $41.9 \%$ had performed BSE in the past and $7.6 \%$ of them performed it regularly and Montazeri et al. (2008) study found that $63.0 \%$ of the women never performed a BSE in their lifetime. In the present study, majority of participants (97\%) reported that they had hear about breast cancer but only $26 \%$ of them performed BSE. These findings are support by Akhtari-Zavare et al. (2013) that reported $97 \%$ of the participants heard about BSE, only $36.7 \%$ stated that they performed BSE and among those who practice BSE, most of them practice BSE occasionally $(50,57.5 \%)$. Similarly, in a study from Turkey reported less than half of the respondents participated BSE and a few are doing BSE regularly (Andsoy and Gul, 2014). All these studies showed that Asian women have low to moderate knowledge with poor to moderate BSE practice.

This study reported only marital status significantly influenced the BSE practice. These may be due to the fact that married women were more exposed to health care facilities and health care professionals during follow up at pregnancy and delivery. Similarly, in a study from Zahedan, Iran, marital status was found to be a significant factor in the BSE practices (Heidari et al., 2008). In another study that was conducted in 770 female in Semnan and Khorasan provinces, in Iran revealed that there were significant associations between knowledge, attitude and breast cancer screening behaviors with marital status (Harirchi et al., 2012). Variables such as age, education, job, family history of breast cancer and personal history of breast disease of respondents were not shown to be significant factors in the BSE practices. Since independent variables were similar among respondents in this study, they may not be significant for the BSE practice. Another two studies reported targeting socio-demographic variables were not effective for BSE practice (Parsa et al., 2008; Akhtari-Zavre et al., 2013). In contrast, other studies (Montazeri et al., 2008; Harirchi et al., 2012) reported that literacy was significantly correlated with a greater degree of knowledge about breast cancer, and literate women were significantly more likely to perform breast self examination.

The study showed that the main sources of information on breast cancer and breast self-examination were mass media, followed by brochure, friends, doctor and nurse. These findings are support by Gurdal et al. (2012) that stated radio and television as the main sources of information for breast cancer and BSE practice among female students at Namık Kemal University, in Turkey. Another similar studies found that nearly half of the students reported their main sources of information on breast cancer and BSE was the media (Noroozi et al., 2011; Redhwan et al., 2011). In contrast, Alipour et al. (2012) reported using the short message service (SMS) via cell phone had a significantly better effect in improving the knowledge about breast cancer and mention as main sources of information on breast cancer.

Results of this study showed that the respondents have low level of knowledge about breast cancer and breast cancer screening. This may be explained by the fact the awareness of breast cancer among the respondents could be attributed to the level of education of the respondents. Similarly, findings of study that was conducted in 216 female in the city of Hamedan, in Iran revealed that $54.5 \%$ of female had poor knowledge of breast cancer (Parsa and Kandiah, 2005). In another study that was conducted in 300 female in the city of Abuja, in Nigeria revealed that $60 \%$ of the female had poor knowledge of breast cancer, $108(37.6 \%)$ had good knowledge and only $16(5.6 \%)$ had an excellent knowledge of breast cancer (Isara and Ojedokun, 2011). Similarly, in a study that was conducted in 240 female who admitted to gynecology-obstetrics outpatient clinic of a private hospital in Gaziantep city, Turkey revealed that $79.2 \%$ of female had poor knowledge on BSE, $62 \%$ and $52 \%$ lack of adequate Knowledge on risk factors and sign of breast cancer, respectively (Karadag et al., 2014). Also, in qualitative study done by Rastad et al. (2012) among 10 women in Kerman city, Iran showed that Lack of knowledge of breast cancer was one of the relevant factors in the process of symptom detection. Increasing knowledge about correct interpretation of symptoms for early detection of breast cancer may lead to a shorter time between symptom detection and seeking medical attention (Rastad et al., 2012).

This study showed that women with higher levels of knowledge about breast cancer symptoms and screening demonstrated higher performance rates of BSE. This is consistent with previous finding suggesting that knowledge of breast cancer screening is an important facilitator for breast cancer screening behaviors (Parsa 
et al., 2011).

There are some limitations in our research. Firstly, the findings cannot be generalized beyond the study sample. Secondly, all data were self-reported with no objective measures to evaluate the women. However, the results of this study provide some understanding on BSE practices among Iranian women.

In conclusion, the results indicate that most women in our study were not well informed on pertinent issues surrounding breast cancer and have poor BSE practices. These data imply that Iranian women need more education on breast cancer early detection particularly on BSE. It is possible, that by knowing how to do thorough BSE, women in general will be able to identify breast cancer at the initial stages. This in turn may help to eventually decrease the number of premature breast cancer deaths in developing countries such as Iran.

\section{Acknowledgements}

The authors gratefully acknowledge editage, who provided editorial and publication support. This study did not receive any specific funding or grants. The authors do not have any conflict of interest to declare.

\section{References}

Ahmadian M, Abu Samah A, Redzuan M, Emby Z (2012). Predictors of mammography screening among Iranian women attending outpatient clinics in Tehran, Iran. Asian Pac J Cancer Prev, 13, 969-74

Akhtari-Zavare M, Muhamad HJ, Rosliza AM, Salmiah MS (2011). Knowledge on breast cancer and practice of breast self-examination among selected female university students in Malaysia. Med Health Sci J, 7, 49-56.

Akhtari-Zavare M, Muhamad HJ, Salmiah MS, Irmi AM (2013). Beliefs and behavior of Malaysia undergraduate female students in a public university toward breast selfexamination practice. Asian Pac J Cancer Prev, 14, 57-61.

Alipour S, Moini A, Jafari-Adli SH, Gharaie N, Mansouri KH (2012). Comparison of teaching about breast cancer via mobile or traditional learning methods in gynecology residents. Asian Pac J Cancer Prev, 13, 4593-5.

Andsoy I, Gul A (2014). Breast, cervix and colorectal cancer knowledge among nurses in Turkey. Asian Pac J Cancer Prev, 15, 2267-72

Canbulat N, Uzun O (2008). Health beliefs and breast cancer screening behaviors among female health workers in Turkey. Eur J Oncol Nurs, 12, 148-56.

Ersin F, Bahar Z (2013). Barriers and facilitating factors perceived in Turkish women's behaviors towards early cervical cancer detection: A qualitative approach. Asian Pac J Cancer Prev, 14, 4977-82.

Fouladi N, Amani F, Harghi AS, Nayebyazdi N (2011). Five year survival of women with breast cancer in ardabil, north-west of Iran. Asian Pac J Cancer Prev, 12, 1799-801.

Giridhara RB, Goleen S, Sharon PC, et al (2011). Asian Pac J Cancer Prev, 12, 1647-55.

Gurdal SO, Saracoglu GV, Oran ES, et al (2012). The effects of educational level on breast cancer awareness: a crosssectional study in Turkey. Asian Pac J Cancer Prev, 12, 295-300.

Habib F, Salman S, Safwat M, Shalaby S (2010). Awareness and knowledge of breast cancer among university students in al madina al munawara region. Middle East Journal of Cancer, 1, 159-66.

Harirchi I, Azary S, Montazeri A, Mousavi SM, Sedighi Z, et al (2012). Literacy and breast cancer prevention: a population-based study from Iran. Asian Pac J Cancer Prev, 13, 3927-30.

Heidari Z, Mahmoudzadeh-Sagheb HR, Sakhavar N (2008). Breast cancer screening knowledge and practice among women in southeast of Iran. Acta Medica Iranica, 46, 321-8.

Isara AR, Ojedokun CI (2011). Knowledge of breast cancer and practice of breast self- examination among female senior secondary school students in Abuja, Nigeria. J Prev Med Hyg, 52, 186-90.

Karadag G, Gungormus Z, Surucu R, et al (2014). Awareness and practices regarding breast and cervical cancer among turkish women in gazientep. Asian Pac J Cancer Prev, 15, 1093-8.

Lamport L, Andre T (1993). AIDS knowledge and responsibility. Youth and Society, 25, 38-62.

Loh SY, Chew SL (2011). Awareness and practice of breast selfexamination among Malaysian women with breast cancer. Asian Pac J Cancer Prev, 12, 199-202.

Montazeri A, Vahdaninia M, Harirchi I, et al (2008). Breast cancer in Iran: need for greater women awareness of warning signs and effective screening methods. Asia Pac Fam Med, 7, 1-6.

Mousavi SM, Gouya MM, Ramazani R (2009). Cancer incidence and mortality in Iran. Ann Oncol, 20, 556-63.

Noroozi A, Jomand T, Tahmasebi R (2011). Determinants of breast self-examination performance among Iranian women: an application of the health belief model. J Canc Educ, 26, 365-74.

Parsa P, Kandiah M (2005). Breast cancer knowledge, perception and breast self-examination practices among Iranian women. Int Med J, 4, 17-24.

Parsa P, Kandiah M, Mohd Zulkefli NA, et al (2008). Knowledge and behavior regarding breast cancer screening among female teachers in Selangor, Malaysia. Asian Pac J Cancer Prev, 9, 221-7.

Parsa P, Kandiah M, Parsa N (2011). Factors associated with breast self-examination among Malaysian women teachers. Eastern Mediterranean Hlth J, 17, 509-16.

Rastad H, Khanjani N, Kalantari Khandani B (2012). Causes of delay in seeking treatment in patients with breast cancer in iran: a qualitative content analysis study. Asian Pac J Cancer Prev, 13, 4511-5.

Redhwan AA, Dhekra HA, Yuri V BB, et al (2011). Practice and barriers toward breast self-examination among young Malaysian women. Asian Pac J Cancer Prev, 12, 1173-8.

Smith RA, Cokkinides V, Brawley OW (2009). Cancer screening in the United States, 2009: a review of current American Cancer Society guidelines and issues in cancer screening. Cancer J Clin, 59, 27-41.

Suh MA, Atashili J, Fuh EA, Eta VA (2012). Breast selfexamination and breast cancer awareness in women in developing countries: a survey of women in Buea, Cameroon. BMC Res Notes, 9, 627.

Yilmaz D, Bebis H, Ortabag T (2013). Determining the awareness of and compliance with breast cancer screening among Turkish residential women. Asian Pac J Cancer Prev, 14, 3281-8.

Yurdakos K, Gulhan YB (2013). Knowledge, attitudes and behavior of women working in government hospitals regarding breast self-examination. Asian Pac J Cancer Prev, 14, 4829-34. 